\title{
Kommission Hüftsonografie SGUM/SVUPP
}

Momentan ist es relativ ruhig betreffend die Belange der Hüftsonografie. Im Hintergrund wird aber gearbeitet und eine internationale Taskforce bereitet eine Standardisierung der Hüftsonografie vor, insbesondere auch über die Anforderungen an die Teacher, an die

Kurse und an die Methode selbst.

In dieser Taskforce ist zusammen mit den wichtigsten Ländern Europas auch die
Schweiz durch Mitglieder unserer Kommission vertreten.

Beat Dubs

Präsident Kommission Hüftsonografie 